\title{
Norms Contestation: Insights from Morphogenesis Theory
}

\author{
Saira Bano
}

\begin{abstract}
Critical constructivists have introduced the concept of "contestation" and have argued that norms not only have a constitutive dimension, but also a structural dimension. Norms entail a 'dual quality' in which they are constructed with discourses, but at the same time structure the discourses that hold their meanings (Wiener 2008). The critical constructivist approach has broadened the current understanding of norms but it is silent about the relationship between flexibility and stability. It is important to know how far the meanings can be contested and how fairly stable international norms retain influence in the face of this contestation. This paper analyses how far Morphogenesis theory by Margaret Archer can help to solve this problem. Morphogenesis theory is capable of comprehending the flexibility and stability of norms leading to elaboration or maintenance of a system. In order to explore the empirical utility of morphogenesis theory in norms contestation, the paper assesses the evolution of the India-US nuclear deal, which was concluded in defiance of nuclear nonproliferation norms. This study argues that constructivist theory based on the analysis of such norm competition and adaptation may be able to overcome the problem of focusing on stability to the point of denying mechanisms for social change.
\end{abstract}

Key Words: constructivism, norms contestation, morphogenesis theory, agent-structure debate, power, culture

$\mathrm{N}$ orms gain force through socialization and become institutionalized through a derivative and highly political process of interaction between shared knowledge, material resources, and practices prevalent among states as well as the interests of individual actors. To understand change in international norms some have suggested that, "a new norm gains legitimacy with the rule community when it is itself a reasonable behavior response to the environmental conditions facing the members of the community and when it "fits" coherently with other prevailing norms" (Florini 1996). Others have proposed a process of norms

*Saira Bano (maida.soha@gmail.com) is a PhD candidate in Centre for Military and Strategic Studies (CMSS) at the University of Calgary, Canada. Her research focuses on International Relations Theories and the nuclear nonproliferation regime. She has won several academic and research awards. She was awarded the prestigious Joseph-Armand Bombardier Canada Graduate Scholarship Doctoral by SSHRC (Social Sciences and Humanities Research Council). She was also awarded Graduate Research Award by the Simons Foundation and Kodikara Award by RCSS.

The Korean J ournal of International Studies Vol.13-1 (April 2015), 1-28.

http://dx.doi.org/10.14731/kjis.2015.04.13.1.1

(c) 2015 The Korean Association of International Studies 
cascade (Finnemore and Sikkink 1998), or spirals (Risse, Ropp, and Sikkink 1999), the notion of normative shifts (Bell 1999), and finally processes of persuasion, argumentation, and pressure as a means of norm diffusion (Risse 2000).

The different stages in the norm cycle have a progressive design, and stepping backwards seem to be impossible. Critical Constructivism has introduced the concept of "norms contestation", which underlines the need to go beyond the traditional understanding of international norms - a potentially static understanding in which norms are mostly black boxes regulating states' behaviour or constituting states' identity.

Critical Constructivism highlights the importance of the context and practice of norms, a dimension, which is largely ignored by Constructivist research on norms so far. It treats norms as a dynamic, flexible phenomenon. Norms are flexible but at the same time remain stable over a longer time. Wiener notes, "while norms may acquire stability over extended periods of time, they remain flexible by definition" (Wiener 2007). Wiener does not conceptualize stability in a similar way to flexibility and therefore, it remains unclear how flexibility (norm is adjustable to changing circumstances) and stability (norms act as rules rather than reasons) are related to each other. Interpretation and meaning are regarded as a prerequisite for successful acceptance of a norm. Different interpretations, developed in social interaction, give meanings to a norm (Wiener and Puetter 2009). Critical constructivism, however, excludes the possibility of opposing a norm and how this opposition can affect the stability of a norm. Critical constructivism also ignores the role of power in norms contestation. Critical constructivists assume that all stakeholders have equal access to contestation but have failed to take into account the fact that norms contested and interpreted by powerful states have different impacts as compared to those contested and interpreted by weak states. Although Wiener recognizes that contestation results from the interaction between individual interpretation and a mutual, shared understanding of a norm (Wiener 2007), she does not further explore the relationship between individual interpretation and intersubjective "oughtness".

Margaret Archer's Morphogenenesis theory looks at the processes of cultural shifts as a matter of contestation among competing groups. This may give some leverage on the processes and outcomes of norm contestation. In order to highlight the limitation of the norms contestation approach and utility of Morphogenesis theory this study assesses the India-US nuclear deal. After the India-US nuclear deal, India is the only country that is getting the benefits of nuclear energy along with its nuclear weapons program. The NPT (Nuclear Nonproliferation Treaty) is a nearly universal (except for four countries: India, Pakistan, Israel and North Korea) treaty and the cornerstone of the global non- 
proliferation regime. The NPT is a bargain between NWSs (Nuclear Weapons States) and NNWSs (Non Nuclear Weapon States) in which NWSs agreed to share nuclear technology for peaceful purposes and gradually disarm their nuclear arsenals while NNWSs (non-Nuclear Weapons States) agreed not to develop nuclear weapons and to accept IAEA full-scope safeguards. The indefinite extension of the NPT in 1995 solidified the structural gap in which the nonNPT states (India, Pakistan and Israel) can neither join the treaty as NWS due to the complexity involved in amending the treaty nor can be coerced to join the treaty as NNWSs. India-US nuclear deal is a first attempt to engage any non-NPT state.

This case study is unique in a sense that the United States did not act arbitrarily, but tried to modify the regime in such a way as to pursue its strategic objective regarding India because nuclear nonproliferation is also an important policy objective. It altered the rules of the regime by introducing the Hyde Act, (changing domestic laws for India), the Nuclear Suppliers Group (NSG) waiver for India, (achieving consensus in the NSG after intense diplomacy), and leading to the India-specific International Atomic Energy Agency Safeguards Agreement. This regime objective explains why the U.S., rather than establishing a set of rules that would apply to all states that have not signed the NPT, sought an India-specific exemption and is discouraging others from following suit. The United States modified the nonproliferation regime to conclude the India-US nuclear agreement but presented these changes as India-specific to discourage other states from following this precedent.

Norm contestation approach cannot explain the evolution of India-US nuclear deal. Russia, France, Germany, United Kingdom, Italy were arguing in favor of lifting nuclear sanction against India but these individual interpretation could not result in collective subjectivity. These countries knew that only United States is in a position to lift these sanctions. For weaker actors, norms are more like givens, but for stronger actors, they might be treated as at least potentially variables subject to deliberate adjustment. In this regard, the Morphogenesis theory developed by Margaret Archer, gives a better explanation about the stability or change of normative structures by separating the role of agency, structure, culture and giving importance to material factors. Archer reserves the term "structure" for material phenomena and interests, and focuses on how structural conditioning affect social interaction and how this interaction leads to structural elaboration. She views "culture" as a nonmaterial phenomenon and focuses on how cultural conditioning affects socio-cultural interaction and how this interaction leads to cultural elaboration.

This paper is divided into five sections. The first section analyzes the contribu- 
tion of conventional constructivism in norms study. The second section analyzes the concept of "contestation" and how it has broadened the study of norms by focusing on the processes of norm development. The third section presents morphogenesis theory and explores how this can conceptualize stability and flexibility leading to a normative change. The fourth section describes the India-US nuclear deal and how this deal has contested the core norms of nuclear nonproliferation regime. This study concludes that Morphogenesis theory, by separating the role of agents, structure and culture, can better comprehend the complex dynamics of normative stability and change.

\section{CONVENTIONAL CONSTRUCTIVISM}

Conventional Constructivism follows the logic of appropriateness and views norms as standards of appropriate behavior. The emergence of norms, their influence on states, and variations in state behavior are the main focus of scholars working towards this end of Constructivism. There are two broad branches in Conventional Constructivism. The first branch focuses more on the global normative structures that come to be constitutive of state identities and interests. The second branch focuses on the agency (and structures) involved at the domestic level in cases of normative change.

Finnemore and Sikkink provide a classic study in the first branch of scholars, drawing attention to the notion of a "norm life-cycle" (Finnemore and Sikkink 1998). They argue that there are three phases in the process of norm diffusion: norm emergence, norm cascades, and norm internalization. The first stage, norm emergence, involves norm entrepreneurs promoting and framing a new norm. Through the efforts of norm entrepreneurs, norms make the transition to a critical mass of adherents, leading to a "tipping point" after which the norm achieves a certain level of prominence. The second stage, norm cascade, involves states being socialized into the new norm and promoting norm compliance. The final stage, norm internalization, is when the norm is taken for granted and no longer publicly debated.

The first branch of Constructivists has traced the development and evolution of many international norms. Studies have focused on, for example, the rise of the international norms for election-monitoring (Kelley 2008), the nuclear taboo (Tannanwald 1999), or the chemical weapons taboo (Price 2007). Apart from these successful evolutions of international norms, scholars have also assessed international norms that have failed to develop, such as the anti-whaling norm (Bailey 2008). Attempts have also made to analyze those international norms 
that are established but the definition and meanings of which have changed over time, for instance regarding the use of force (Alkopher 2007). The processes of treaty development have been identified as one way to trace the development of an international norm, for example the negotiations for the Convention against Torture (Hawkins 2004).

Having established the presence of certain international norms and broader normative regimes in the international sphere, first branch Constructivists also paid attention to how exactly norms "shape actors and agency in world politics" (Farrell 2002, 56). Dimitrakopoulos suggests that international norms have both problem-solving and legitimising dynamics. The author claims that international standards "affect political outcomes by providing a menu of legitimate forms of action from which actors choose those that are considered likely to solve a given political problem" (Dimitrakopoulos 2008, 330).

Finnemore suggested that in order to understand the interests of states we need to appreciate the wider social structure in which states are embedded. These "dense networks of transnational and international social relations" then socialize states to want particular things (Finnemore 1996a, 2). Within these structures, states mold their view of the world as well as their understanding of their particular role in it. Therefore, State interests are seen to be constructed through this process of social interaction and "in the context of internationally held norms and understandings about what is good and appropriate" (Ibid.). Over time as the normative context changes there are corresponding alterations in state interests.

Examples of second branch studies include works by Jeffrey Checkel, Amitav Acharya, and Jeffrey Legro. Jeffrey Checkel is critical of the first branch of Constructivist work as lacking a theory of domestic agency, so that it cannot explain the variation between different states' reception of international norms (Checkel 1999, 85). He advocates a theory of the complex learning process through which agents learn "new logics of appropriateness" and adopt that appropriate behavior even in the absence of material factors (Ibid., 90). $\mathrm{He}$ argues that by looking at domestic conditions, one can predict whether a norm will be successfully integrated in a particular state through the "cultural match" between local norms and the international norm or not.

Jeffrey Legro advocates a similar idea of "organizational culture" and argues that states adopt an international norm if an organizational culture is compatible with that norm (Legro 1997). Amitav Acharya criticizes Checkel's "cultural match" concept, and Legro's "organizational culture", for being too static and proposes his own theory based on constitutive localization. He argues that local actors not only adopt but reconstitute international and local norms in order to make them congruent with domestic structure. In this way, the local actors play 
an important role in making international norms "localized" and internalized (Acharya 2004).

Apart from these two branches of scholars, some Conventional Constructivists present work halfway between the first and second branches of Constructivism. For example Risse, Ropp and Sikkink's edited volume attempts to incorporate attention to the local level but it does so on the basis of a number of assumptions associated with the first branch. The authors present a five-phase "spiral model" of human rights development applied to initially norm-violating countries. In the model a state is thought to pass through the stages of repression, then denial, tactical concession, prescriptive status and rule-consistent behavior. Once the international norms are internalized into the domestic practices of the state the authors argue that they form part of their "taken-for-granted" behaviour, significantly reducing the impact of individual state leaders (Risse et al. 1999).

Thus, while Conventional Constructivism provides many illuminating contributions with regard to international norms, including the need to consider factors such as the nature of the norm, the stage at which it is located in the norm life-cycle, and how international norms are influential by means of socialization and identity, there are areas where significant limitations are apparent. First, the focus is often on international norms where, when they achieve a certain status, meaning is held constant. The "cycle" privileges emergence over decline, and does not easily account for changes in the meaning of norms as they go through the various stages, or indeed continue to change even once the cycle is completed and they are internalized. Norm internalization is problematic for empirical research in IR because it eliminates the possibility of strategic thinking by states in relation to international norms and rules. It leaves no room for instrumentalism around norms and so cannot account for norm violation, the strategic manipulation of norms, and the productive process of norm innovation. Second, there appears to be a degree of permanence suggested with regards to compliance behaviour. Yet their approach begins from the premise, however, that there is always room for change in interpretation, as human agents change and, as well, the different normative regimes that are interacting at any one time.

\section{CRITICAL CONSTRUCTIVISM}

Critical constructivism considers language as a form of action in which use of historical analogies creates certain parameters for action within which actors are located (Fierke 1996). Onuf argues that language and rules are mechanism for forming an intersubjective structure for mutual understanding (1989). The focus 
on language helps to uncover the processes of social construction of reality and identities and norms which then create the rules of a game and affect the parameters for action. Therefore, the power of language is enabling and constraining tool. Language is constituted by competing set of meanings and actors draw on alternative terms to justify their actions. Emphasis on the generation of meaning, norms and rules through interpretation is highlighted in order to determine the cause of norms defection and contestation.

Norms establish rules of game through intersubjective meaning and enable actors to pursue their interests within that structure. It allows the "actors to direct their actions towards each other, communicate with each other, appraise the quality of their actions, criticize claims and justify choices" (Kratochwil 1993, 76). Norms render action meaningful and form the basis for justification and reduce complexity. Therefore, norms are influential on actors but not in the same stable, isolated, and causal manner that tends to be found in the Conventional Constructivism. Critical Constructivists emphasize that norms, at any level (institutional, domestic, or international), are not internalized by actors as has been the case in much Conventional Constructivist thought (Onuf 1998). Rather Norms remain contested through out their life.

\section{NORM CONTESTATION}

With regard to norms Antje Wiener explains the differences between the conventional and critical constructivist approaches. She notes that scholars working in the conventional constructivist approach employ a largely behaviorist tradition to determine the impact of regulative and constitutive norms on state behavior and treat norms as relatively stable causes for action. The focus is on norms' influence to state behavior. This is in contrast to the more reflexive approach to norms in which norms are seen as contested and the focus is on the construction of norms in practice. The concern is with contested meaning as located in practice. Attention is shifted to "variation in the interpretation of meaning in the different domestic context where compliance with a norm is expected" $(2004,199)$ as opposed to making assumptions that they are understood and interpreted uniformly at domestic levels. This brings into focus questions surrounding the "impact of variation in the meaning" of norms (Wiener 2004, 200) as opposed to their direct influence where meaning is taken as stable even across context. This variation in meanings can be accounted for through analyzing "official documents, policy documents, political debates and media contributions" $(2004,201)$ and through elite interviews (Wiener 2008). 
Stable norm structure behavior eliminates the very processes of construction of meaning. Norms are "contested, unless and until a mutually satisfactory interpretation is established through discursive intervention which may or may not be conflictual" (Wiener 2004, 202). Every norm has specific cultural and social context which gives rise to different interpretations and results in contestation (Wiener 2009). Contestation is not detrimental to normative structure but lends greater flexibility. "Contestation is central for establishing the legitimacy of compliance processes" and "it is constitutive towards social legitimacy" (Wiener 2004, 218). Norms do exhibit a certain degree of stability, as they are recognizable by the common expectations that they structure. However, norms are also in a constant state of dynamism and flux. Even stable norms require constant actions to reify their existence. States must undertake the behavior that makes social norms intersubjectively real. "Norms are born anew everyday through the actions of political actors" (Hoffmann 2010, 5419). It is through processes of contestation that norms are applied and interpreted, and thus are affected in the scope and detail of their meanings.

Norms are contested at every turn - in their emergence, as actors are socialized, and even once they are established and internalized. Contestation is inherent in the process through which actors interpret intersubjective notions of appropriateness, act on that understanding (engendering political outcomes), and, in turn, alter intersubjective notions of appropriateness. It is through interpretation and action based on interpretation that norms emerge and change over time. Gregg $(2003,22)$ argues, "the very identity of a norm first emerges with its interpretation. Because it is interpretative, identity is variable and changeable, never settled. Meaning is created time and again." Similarly, Jacobson $(2005,57)$ claims, "different contexts.... generate different interpretative possibilities and plausibilities." When diverse actors interpret a norm, diverse understandings are inevitable.

The principle of norm contestation also lies at the core of Sandholtz's cyclic model of norm change. According to this, disputes over the context-dependent application of norms are inevitable due to the indeterminacy and contradictions inherent in norms. Normative change, however, does not come automatically but is thought to be triggered by disputes arising from applying a norm to a specific situation or in reaction to triggering events or acts (Sandholtz 2007, 9-23). External events upset the existing international order, which may render normative commitments obsolete and pave the way for the establishment of new or the remodeling of existing norms. Norms change can also be caused by new or altered norms arising from transformations in the international distribution of power (Sandholtz and Stile 2009, 325). 
Florini (1996) compared norm contestation with genetic evolution. She argued that norms' contestation, like genetic evolution, is not merely a part of the process of norm development but is inevitable. The genetic analogy suggests that, as with any unit subject to selection, three factors account for the reproductive success or failure of a contest norms: (1) whether a norm becomes prominent enough in the norm pool to gain a foothold; (2) how well it interacts with other prevailing norms with which it is not in competition, that is, the - normative environment; and (3) what external environmental conditions confront the norm pool. No one of these is sufficient to determine the path of a norm's evolution. Each is a necessary but not sufficient condition. ${ }^{1}$

A focus on norm contestation has certain methodological advantages. It offers a more accurate image of global realities, since norms do not exist in a political or normative vacuum. A focus on competition allows one to look specifically at the interaction and the constitutive effects of norm. According to Finnemore, the "tensions and contradictions among norms leave room for different solutions and different arguments, each of which makes legitimate claims based on the same norms" (Finnemore 1996b). As new norms emerge through competition, decisions taken at the point of contention may appear to contradict or deviate from the prevailing interests and the previous known normative framework. Wiener argues that both, behaviorist and reflexive, approaches are important to comprehend the norm changes. "Exploring the construction and change of norms within their socio-cultural contexts conveys one part of the story, while studying the role of norms as causing rule-following behavior conveys the other". She suggests that both are important to take into account "the dual quality of norms as stable and structuring, on the one hand, a flexible and constructed, on the other" $(2007,51)$.

While this current trend in the study of norms goes beyond a static understanding of norms, it does not focus on the processes of normative change. Critical Constructivism, despite its important insights into contestation and the interpretation of norms, does not deal with the interrelations between flexibility and stability. The flexibility of norm meaning implies that a norm can provide the foundation of international agreements and be commonly agreed upon, yet its meaning can differ between contexts and in practice. Flexibility is defined as if the norm is adjustable to changing circumstances. The idea of norm stability commonly equates to the concept of norms as rules rather than reasons: actors understand and know their obligations. The following section will suggest

\footnotetext{
${ }^{1}$ Bjorkdahl criticized Florini's biological analogy for disregarding the diversity and coexistence of norms as "some compete, some are synergistic, some are cooperative or symbiotic, some die of their own accord” (2002, 56).
} 
Morphogenetic theory focused on the question of stability and change in normative structures and contents, can contribute significantly to our understanding of the processes and outcomes of norm contestation.

\section{MORPHOGENESIS THEORY}

Constructivists emphasize the mutual constitution of agents and structure. Alexander Wendt argued that Kenneth Waltz's (Waltz 1979) international structure can only constrain state agency but cannot generate state agents (Wendt 1987). Wendt imported Anthony Giddens Social Structuration theory (Gidden 1984) and Roy Bhaskar's critical realist theory (Bhasker 1979) to demonstrate that social structures are "constituted by the practices and self-understandings of agents" and "agents, in their own turn, are constituted and therefore explained by structures" (1987, 359). Similarly, David Dessler challenged Waltz's "positional model" with a "transformational model" of international structure, in which social actions regenerate social structure (1989). Walter Carlsnaes also criticized Wendt that he has conflated agent and structure in such a way that made it difficult to do empirical research. Carlsnaes's important contribution was to invoke Margaret Archer's morphogenesis theory in order to introduce the time dimension to the agent-structure debate. He argued with special reference to foreign policy, that what is needed to explain an action is "indicating the reciprocal interplay over time - in terms of developmental patterns or cycles - that exists between structure and action" (1992, 264).

In Archer's Morphogenesis theory, the main insight is that "structure necessarily pre-dates the action which transform it; and that structural elaboration necessarily post-dates those actions." Thus Morphogenesis breaks the flow of the recursion of social life into intervals and accords "full significance to the time scale through which structure and agency themselves emerge, intertwine, and redefine one another" $(1995,76)$. In other words, Archer argues that structure and agents are interdependent but they operate on different timescales. At any particular moment structures constrain and enable agents, whose interactions produce intended and unintended consequences, which leads to structural reproduction or transformation of the initial structure (Archer 1996).

Figure I presents a simplified model of the elements of Morphogenesis Theory. According to Archer, the ontology of social structure is tripartite: structure, culture, and agents. Although they interpenetrate and involve in every social interaction, they are analytically distinct. Archer recognizes the complexity of society and separates the structural and cultural domains which are autonomous and 
substantially different from each other (Archer 1996). She recognizes the interplay between structure and agency on the one hand, and culture and agency on the other hand to facilitate a greater understanding of the interplay between them. As a consequence, Archer's methodological approach becomes analytical dualism, which emphasizes the necessity of studying the interplay between the two levels without conflating them. This applies to the interplay between structure and agency as well as to that between culture and agency (Archer 1995).

Analytical dualism distinguishes a cultural system from socio-cultural interaction; this distinction is upheld while the analysis moves through the three phases of the morphogenetic cycle. On one level, the cultural system consists of logical propositions, which may be either contradictory or complementary, while on the other level socio-cultural interaction consists of matters of the interpersonal cultural system; sociocultural interaction is the decisive factor influencing whether Morphogenesis or Morphostasis - elaboration or maintenance - prevails (Archer 1996).

\section{STRUCTURE}

Structure involves material resources as well as the broad social system. This covers the different placement of states with regard to differing levels of resources within the international system. Structure also includes institutions and how they structure behavior. It also conveys expectations to be met in a specific role. Powerful states construct institutions to reinforce their position and norms, embedded in these institutions, serve their interests.

Norms are created by states but they also guide state conduct. Norms and interests are no opposites. Many norms empower states to pursue interests that have been legitimate. Norms and interests penetrate each other and depend on each other. In this way norms that serves great powers' interest and therefore supported by them show more stability. The great powers, in particular, are seen as having a great impact on the creation, maintenance or change of international norms. Great powers have the capabilities to create new norms useful for legitimizing their own actions even though these norms may violate already established norms (Brooks and Wohlfort 2005, 516-19). As well, Nevers argued that power plays an important role in norms enforcement. Great powers coerce weak states and pursue strong states to promote new norms (Nevers 2007, 53).

Norms that serve great powers' interest are considered to be stable. Great powers, on one hand, ensure norm compliance by using coercive as well as diplomatic means but, on the other hand, reserve for themselves the right to violate norms if that norm is in conflict with their perceived national interests. For example, the United States reserves the right to norm deviance if its government deems this 
necessary in order to live up to the exceptional "special responsibility" of a hegemon (Foot and Walter 2011, 284). Norm stability also depends on how well a norm is defined and how well it is institutionalized. Legro (1997) devised a measure of norm strength based on specificity (how well the norm is defined), durability (how long it has been in effect and whether violations have been penalized), and concordance (how widely it is accepted in diplomatic discussions and treaties).

\title{
CULTURE
}

Culture involves the "world of ideas", values, beliefs, and ideology. Archer writes:

\begin{abstract}
At any given time a cultural system is constituted by the corpus of existing intelligibilia - by all things capable of being grasped, deciphered, understood or known by someone. By definition the cultural intelligibilia form a system, for all items must be expressed in a common language (or to be translatable in principles) since this is a precondition of their being intelligible (Archer 1996, 104).
\end{abstract}

It is necessary to consider how contextual conditions affect norm emergence and evolution independent of the content of the norms. There are contextual conditions where norms will arise, regardless of the content of the rules. The social context that the agents find themselves in is a key determinant of the influence of norm entrepreneurs as well as the structural patterns that emerge. When the social context is too complex, agents may not find intersubjective agreement, even when helped by the suggestions of a norm entrepreneur because they cannot discern what the appropriate behavior should be. Social complexity will be related to: the number of competing ideas, the range of interpretations agents have of the social context, the power of the entrepreneur, the power of initial proponents that the entrepreneur convinces, and the history of the issue at hand among.

When the social context is complex, widely shared; norms may have difficulty arising regardless of the activities of norm entrepreneurs. A norm that fits readily into an existing set of other norms is less likely to change as compared to a norm that seems to stand at odds with other norms, and thus in a degree of tension with them. Similarly, presumably a new interpretation of a norm that brings it into closer agreement with existing norms may be favoured (ceteris paribus) over one that tends to increase tension with or divergence from other norms.

Morphogenesis involves three phases, (I) structural or cultural conditioning, (II) social or sociocultural interaction, and (III) structural or cultural elaboration. Cultural conditioning is understood as the ideas which at any given time have 
holders. Only if ideas have holders can they have any effect on agency. The cultural system thus creates a situational logic for agents. But Archer emphasizes that cultural conditions cannot determine whether cultural change will take place. Change presupposes sociocultural interaction, and interaction will be characterized by attempts to protect or increase vested interests. Thus, sociocultural interaction is determined by material interests.

Therefore, the decisive question becomes how the two levels, the cultural system and sociocultural interaction, combine. It is of little value that the cultural system is riven with inconsistencies demanding change, if the distribution of power is such that any attempt at change can be suppressed. It is of no use either that the cultural system is characterized by complementarities which involve ample opportunities for adding new elements to the already existing cultural system, if holders of power use all means to prevent this. In this way, the second phase of the morphogenetic cycle - sociocultural interaction, the use of power and the escape from power - is decisive for whether the outcome turns out to be Morphogenesis (changes in culture) or Morphostasis (stability).

According to Archer, it is possible under well-ordered sociocultural conditions to suppress changes for some time, but in long run it becomes impossible. At some point in time a situation will arise where even the cultural elite will see its own interest in accepting the demand for a revision of culture in order to minimize inconsistencies, or a situation where it will be forced to accept new cultural items in order to uphold its position. Sooner or later the third phase of the morphogenetic cycle will become reality.

\section{AGENTS}

For Archer, agents play an important role in Morphogenesis. Since social conditioning is only efficacious through agents. Hence, there is a social interaction as the structure and agents engage and there is a sociocultural interaction as the culture and agents engage. Agents have "two defining features: they modify the capabilities of component members and exert causal powers proper to their relations vis-à-vis other agents or groupings" (Archer 1995, 184).

In Being Human: The Problem of Agency, Archer provides more clarification about agents. She emphasizes the role of agents as "active shapers of their sociocultural contexts", stating that "the very notion of Morphogenesis is predicated upon such active agents" (Archer 2000, 308). Agents can shape and reshape the structure in which they find themselves. According to Archer, there are three phases of agency. The first phase is "primary agents" which refers to the position of agents in sociocultural system. The second phase is "corporate agents" which have say in how a structure gets elaborated. In elaborating this "say", she writes: 
Only those who are aware of what they want, can articulate it to themselves and to others and have organized in order to obtain it, can engage in concerted action to reshape or retain the structural and/or cultural features in question (Archer 2000, 265).

The second phase has active groups that mobilize for change, but power relationships can long prevent restructuring among corporate agents. As long as elites do not support the primary agents, no change will take place. The third phase involves "social actor". This is the only phase which refers to an individual and not a group. The social actor is an individual who occupies a role that places him in a decision-making position (Archer 2000, 284).

These three phases of agency help us to look at public debate (primary agents), elite perception (corporate agents) and leadership style (social actor). An analysis of norm stability or flexibility must capture public opinion and political elites' perception of national interests. Shannon and Keller (2007) argue that leadership style is related directly to the violation of international norms. The authors propose that a violation is in fact heavily influenced by the beliefs and decision-making styles of leaders. Two areas are considered in determining leadership style how sensitive actors are to the "political context and how they view the international environment". If actors are insensitive to the political context, and view the world in terms resembling a Hobbesian state of nature, then they are considered to have a motivation to violate. Those leaders considered to be more sensitive to their political context and with a more favorable world outlook are deemed to be less likely to violate international norms. If actors have both the will and the ability, violation is considered to be a more likely course of action.

Regarding sensitivity to political context and worldview: things become more complex if one differentiates between, e.g., a national and an international political context, which may disagree with each other. An actor may thus be sensitive to a domestic political context (including prevailing domestic norms) which leads it to see a clash with prevailing international norms (which, in fact, the actor may deny or seek to re-interpret).

Shannon suggests that in cases of norm violation, actors try to interpret the situation in such a way as to mitigate the restraints of the norm so as they are able to justify the violation as "socially acceptable". This is particularly important if international social standing is of great value to the actors, and as a consequence violation will only be possible if there is sufficient room for interpreting the norm or situation in such a fashion that it is capable of being presented with a plausible justification, not simply presented as a violation. In this sense the "parameters of a norm indicate under what situations the norm's prescriptions will apply" 
(Shannon 2000, 295).

TIME

Archer emphasizes the interplay of agent, structure and culture over time. In Figure I, at T1, structural and cultural conditioning is already set up before human actors with particular intentions, concerns and projects, and located in particular roles and positions in institutions begin interacting with each other in $\mathrm{T}_{2}-\mathrm{T}_{3}$ (social and socio-cultural interaction). It is at the second stage of the morphogenetic cycle that human agency is exercised. Some institutional roles are necessarily related to each other, while others are contingent on the context. Exactly what emerges from a particular period of social/ socio-cultural interaction (T2 $\mathrm{T}_{3}$ ) is contingent on the context of the situation and cannot be predicted. Analytic histories of particular contexts are required to explain the outcomes of social interaction which may be structural and cultural change or reproduction at $\mathrm{T} 4$.

The meaning of a norm is highly dependent upon historical contingency relating to the constitutive practices within a society that provide reference frames for meaning. It is important to take into account the phases through which norms have developed and how structural, agential and cultural factors have brought changes or stability in a norm.

\section{SITUATIONAL LOGIC}

Apart from this structure, culture, and agents within social change, Archer adds another basic concept: "situational logics". A situational logic arises out of the relationship between the conditions inherent in the structure and culture, which provide direction for agents during the phases of social and socio-cultural interaction. At its core, a situational logic predisposes the agents to act in a manner consistent with protection, correction, elimination, or opportunity (Archer 1995, 303).

The four different situational logics arise from the relationship between structure and culture; each of which leads to a different logic. When the relationship is of necessity and cannot be undone under circumstances, then it is in the best interest of states to maintain the status quo since disruptions would result in mutual losses. The mutually beneficial situational logic inhibits innovation and thus complementary relations ensure the maintenance of the vested interests of all states. The situational logic promotes "protection" and results in morphostasis.

If the necessary relationship is one of incompatibility or conflict, then "correction" is the favored situational logic. This kind of context conditions states towards "strategic action" in order to shift the context towards a more compatible structure. Thus, while one set of states might occupy themselves by working towards the realization of their vested interests by working towards change, 
another set of states will be motivated to work for the containment of dissent through devising a compromise within the structural context. States have identified an inconsistency of concern but remain committed to unity and seek to repair the inconsistency in order to preserve the status quo. This results in morphostasis.

If the contingence relationship is one of incompatibility or conflict, then "elimination" is the favored situational logic. In contingent incompatibilities both sides become party to the situational logic of elimination, where the greatest gains coincide with inflicting maximum injuries on the other side. Thus, the strategic mobilization of material and resources generates new forms of social cleavage. This results in morphogenesis.

If the contingent relation is one of compatibility or agreement, then "opportunity" is the favoured situational logic. States within the system will endeavor to extract gains from available structural opportunity since it may imbue the current structural context with resources which may enable some agents to realize their interests. This undermines the stable distribution or delicate balance upon which both types of morphostatic formations depended and results in morphogenesis. Given the complexity of social system, there are multiple combinations of these situational logics affecting the variety of interactions in which agents find themselves.

Morphogenesis theory can explain the complex dynamics of norms, showing how far a norm is stable or flexible by looking at structure, agents, and culture in different time phases. Structure and culture create opportunities and constraints for action and agency handles opportunities and constraints to produce change or maintain the status quo. In this way Morphogenesis Theory can explain the importance of particular agents in generating change in patterns of international politics. It can also look at structural constraints on agency and mechanisms through which agency might generate change. India-US nuclear deal explains how the United States was able to change the nuclear nonproliferation norm for India to pursue its strategic interest against China. This case study explains that Washington was powerful enough to lift international nuclear trade sanctions against New Delhi, it was also constrained by the structural factors in which it had to get exemption for India in order to minimize the damage to the regime.

\section{THE INDIA-US NUCLEAR DEAL}

On July 18, 2005, U.S. President George W. Bush and Indian Prime Minister Manmohan Singh in a joint statement announced a framework for nuclear cooperation between the two countries, which brought an end to more than three 
decades of sanctions against India following its 1974 nuclear test. The United States had to change its domestic law and modify the nuclear nonproliferation regime to facilitate this nuclear cooperation. It altered the rules of the regime by introducing the Hyde Act, (changing domestic laws for India), the Nuclear Suppliers Group (NSG) waiver for India, (achieving consensus in the NSG after intense diplomacy), and leading to the India-specific International Atomic Energy Agency (IAEA) Safeguards Agreement.

T1 encompasses the history of interactions that have led to a conditioning of structures, cultures and agents. Collectively these conditions comprise the context of a given change. The structural and cultural conditioning is the first stage of morphogenesis theory. The non-proliferation nuclear order is based on the United States Atomic Energy Act (AEA) of 1954, the NPT, the safeguards systems applied by the IAEA, and the Nuclear Suppliers Group (NSG). This order was based on the understanding that the benefits of civil nuclear power carry the potential threat of military application, as civilian nuclear programs may provide necessary infrastructure, know-how, and training that can be utilized to manufacture nuclear weapons. The IAEA safeguards system and the NSG export controls were established to prevent the proliferation of nuclear weapons as a byproduct of civilian nuclear cooperation.

The NPT opened for signature in 1968 and came into force in 1970. The NPT, at the heart of the nonproliferation nuclear order, recognizes the five Nuclear Weapon States that had tested nuclear weapons prior to January 1, 1967. Other states could only join the NPT as Non-Nuclear Weapon States, renouncing their right to manufacture or otherwise acquire nuclear weapons and accepting safeguards over their peaceful nuclear activities. The treaty permits the commercial usage of nuclear technology. In this regard the IAEA safeguards system works hand-in-hand with the nuclear export control system to detect and deter misuses of civilian nuclear facilities and materials to build nuclear weapons.

In 1974 when India had its "peaceful" nuclear explosion, it demonstrated that nuclear imports for commercial and peaceful purposes could be used to make nuclear weapons. In response to the Indian nuclear test, the United States took two measures to ensure that peaceful nuclear cooperation could not contribute to nuclear proliferation. First, at the international level, the United States endeavored to establish an effective NSG, with guidelines covering nuclear exports to states without nuclear weapons. The focus was particularly on discouraging exports of sensitive nuclear technologies such as enrichment and reprocessing. Second, at the domestic level, the United States introduced the Nuclear NonProliferation Act (NNPA) of 1978 (amending the AEA), which tightened the criteria for nuclear cooperation. The NNPA imposed tough conditions on nuclear 
exports: full-scope safeguards and the termination of the agreement if a state holds a nuclear test or engages in activities relating to nuclear weapon manufacturing (Squassoni 2008). In 1992, after Iraq's nuclear weapon program was discovered, the NSG adopted the same condition of full-scope IAEA safeguards for nuclear imports.

The requirement of full-scope safeguards excludes any possibility of nuclear trade with non-NPT states - India, Pakistan, and Israel - as these do not accept full-scope safeguards due to their nuclear weapons programs and their standing outside of the NPT. The indefinite extension of the NPT in 1995 and the Indian and Pakistan nuclear tests in 1998 created a structural gap. On the one hand, all world states are NPT parties except India, Pakistan, and Israel (North Korea was an NPT party but withdrew in 2003), and on the other hand, the indefinite extension of the NPT made it permanent. The non-NPT states are neither willing to join the NPT as NNWSs nor can they be coerced to do so; as a result they were omitted from nuclear forums derived from the NPT.

T1 explains the structural set up in which the NPT, IAEA, NSG are created to prevent the spread of nuclear weapons and non-NPT states are not allowed to have civilian nuclear trade unless they give up their nuclear weapons. At cultural level nonproliferation norms provide a structure which civilian nuclear cooperation is allowed only under IAEA full-scope safeguards. In a situational logic India's rising economy provided an opportunity for the nuclear suppliers to revise the nuclear nonproliferation norms. India's growing economy played an important role in improving the relations. Strobe Talbott wrote in 2004 that the French government was eager to have nuclear agreement with India in late 1998. "In September 1998, during a visit by Vajpayee to Paris, President Chirac had announced that France would conduct its own 'strategic dialogue' with New Delhi. The French dangled the possibility that India might, with French help, become eligible for nuclear assistance of the kind forbidden to non-NPT states. If that happened, India would.., have broken free of the restrictions that resulted from its long standing refusal to join the NPT" (Talbott 2004, 143). Italy along with France was also supported the idea to lift sanction on India. "Seeing France and Italy breaking ranks, the United Kingdom and Germany showed signs of being tempted to step up the pace of restoring to normal their own relations with India (Talbott 2004, 143).

In 1998, Russia supplied two reactors to India in violation of NSG guidelines (Hibbs 1998). This issue was raised again in 2001 when Russia supplied low enriched uranium fuel to India's nuclear power station at Tarapur (Hibbs 2001). The Bush Administration "deeply regret" the Russia's decision to ship fuel to India's Tarapur reactor and regarded this action as a "violation of Russia's non- 
proliferation commitments.” The NSG meeting in December 2001 also expressed strong concerns and regarded it as "inconsistent with Russia's commitment" (Reeker 2001). Russia justified the supply on the grounds of the safety exemption, which allows supply "only in exceptional cases when they deemed essential for the safe operation of existing facilities." The NSG interpretation of this clause is to transfer controlled items "only when deemed to be essential in order to prevent or correct a radiological hazard posing a significant danger to public health and safety and which cannot realistically met with any other means" (Thorne 2001, 1-3). According to this interpretation Russian supplies could not be justified under safety exemption clause. When the NSG rejected the Russian argument, Russian Minister for Atomic Energy Eugeny Adamov threatened a Russian withdrawal from the NSG if its nuclear trade was hindered (Radyuhin 2000).

Russia and India enjoy strong strategic, military, economic relations since Cold War and Russia has always been in favor of lifting sanctions against India. In May 2000 Mikhail Ryzhov, a Russian Atomic Energy Ministry's official, argued in favor of the recognition of the nuclear status of India and Pakistan. He said, "India and Pakistan can longer be considered non nuclear weapon states, even though they still have this status under the nonproliferation treaty." He called this situation "unnatural" and need to be addressed in such a way that "it does not promote and encourage further proliferation of nuclear weapons in the world" (The Hindu 2000).

France and Russia wanted the review of NSG guidelines, which prohibit nuclear cooperation to any country that has not accepted full-scope safeguards, to increase nuclear energy cooperation with India. Russia wanted the NSG members to "take into account the new realities" and the NSG guidelines should not be an "obstacle" in civilian nuclear cooperation with India (World News Connection 2003). Russia France, Germany, United Kingdom, Italy knew that without US help it is not possible to lift these sanctions against India and have been proposing this idea but this proposition was dismissed outright by Clinton Administration, which refused to compromise its nonproliferation agenda. Although Clinton administration rejected the idea but it was not possible to suppress these changes for a longer time. According to Archer eventually a situation will arise when even cultural elite will see its own interest in accepting the demand for revision in order to minimize inconsistencies. The Bush Administration officials recognized the strategic importance of India even before coming to office. (Table I)

$\mathrm{T}_{2}$ and $\mathrm{T}_{3}$ is the duration of time when interaction between actors occur that lead to an outcome. For this study T2 is the time when this idea was perceived. During the run-up to the 2000 presidential elections, Condoleezza Rice, who later 
became President George W. Bush's National Security Advisor, wrote in Foreign Affairs that "the United States should pay closer attention to India's role in the regional balance...India is an element in China's calculation and it should be in America's too. India is not a great power yet, but it has the potential to emerge as one" (Rice 2000). She also emphasized the role of Japan, South Korea and Taiwan in China's containment but in India's case she saw the potential to emerge as a great power; but the Indian nuclear program marginalized its role in the plan to contain China.

In the situational logic the Bush Administration saw an opportunity to boost India's status against rising China. This was not possible without lifting nuclear trade sanctions on New Delhi. President Bush (Social actor) placed less emphasis on international institutions and this leadership style facilitated to materialize this unprecedented policy. The thaw in Indo-U.S. relations led to the unprecedented nuclear deal when Indian Prime Minister Manmohan Singh and U.S. President George W. Bush signed a joint statement on July 18, 2005. This joint statement was the framework of the Indo-U.S. nuclear deal, under which India agreed to undertake several obligations to strengthen its commitment to the nuclear nonproliferation regime and, in exchange, the United States agreed to civil nuclear cooperation (Mohan 2005).

India agreed to separate its military and civilian nuclear facilities, placing the latter under IAEA safeguards; this required an India-specific safeguards agreement with the IAEA. For its part, the United States had to change its domestic law to accommodate a civilian nuclear cooperation agreement with India. This touched on the AEA, which governs U.S. nuclear cooperation with other countries, and Section 123 of which required full-scope safeguards. On December 18, 2006, President Bush signed the Hyde Act into law, to provide a waiver for India from the relevant provisions of the AEA (White House Press 2005). This nuclear agreement revised the culture in which India is now viewed as a "responsible" nuclear state.

As part of the deal, On September 6, 2008, the Nuclear Suppliers Group (NSG) exempted India from its guidelines, making it the first country that had not signed the NPT recently to be allowed to have nuclear trade with NSG members. India received this waiver after tough negotiations. A few NSG members wanted to include strong non-proliferation conditions but failed to get these, as they were unacceptable to India. The United States lobbied hard to get such an exemption for India. Some member states were reluctant to reverse this rule for India on non-proliferation grounds, but at the end yielded to the pressure of the major nuclear suppliers (Bano 2011).

Active supporter countries like Russia, France, and Britain, vigorously sup- 
ported the NSG waiver for India and soon after the approval they signed nuclear deals with India. France signed nuclear accord with India on 30 September (BBC News 2008a); Russia which has historically close links, signed a series of agreement even before the NSG approval (BBC News 2007); and on November 10 Britain also lifted its ban on exporting nuclear technology to India at the domestic level (BBC News 2008b). This shows the strong economic motive of these states which wanted to have their profit share in Indian market, made possible by the waiver. Now these countries are supporting India for NSG membership and for that the NSG again has to exempt India for its NPT condition.

Among the passive supporters, Canada, and Australia, though strong supporters of nuclear non-proliferation supported the waiver. Canada had signed a nuclear deal India on June 27, 2008 (Curry 2010). It was a historical shift in Canada's policy after 1974, when it refused nuclear trade with India after India used a Canadian nuclear reactor intended for peaceful uses to support a nuclear test. In Australia the political parties have different approaches regarding the sale of uranium. In 2007, the Liberal Party decided to sell uranium to India, reversing a policy of not selling uranium to non-NPT states. The Labor Party reversed this decision and thus maintained Australian policy. Liberal party again is in power and finally signed the nuclear cooperation on September 5, 2014 (Haidar 2014). It is evident that the passive supporters have strong nonproliferation policies and anti-nuclear public opinion, but their economic interests and good relations with India and the U.S. did not allow them to oppose the waiver.

Japan, a strong supporter of the nonproliferation regime, did not oppose the waiver due to its close relations with the United States. Although at the domestic level Japan faced the criticism from media and nonproliferation activists, it did not block the waiver. Agence France Presse quoted different Japanese newspapers. "Bad precedent for nuclear non-proliferation," the top-selling Yomiuri Shimbun said in a headline. The influential Asahi Shimbun expressed concerns that the vote "would weaken global efforts at nonproliferation." "The decision is hard to understand," the Mainichi said in its editorial. "Japan has helped to weaken the NPT regime," it added. The mayors of Nagasaki and Hiroshima also expressed their disappointment saying that this decision had "made NPT a dead letter" and "It is extremely regrettable that countries concerned, including our country, came to the unanimous agreement," Agence France Presse quoted their statement from Jiji press (Agence France Presse 2008). The United States and France have pressed Japan to sign a nuclear deal with India, because Japanese technology is essential for the completion of nuclear reactors that France and the United States' firms won (Reuters 2010). Japan is negotiating nuclear deal with India but the nuclear testing issue is still a major problem. Japan wants legally 
binding nuclear testing moratorium but India wants to keep this option open (Joshi 2014).

China remained neutral in the NSG meeting and did not participate in the voting. It has improved its relations with India recently. China had assured the Indian government that it would not block the waiver in the NSG meeting (Varadarajan 2008). China's domestic modernization depends on harmonies relations with the outside world. China went along the decision so as not to antagonize the United States and others. The anti-waiver "like-minded" countries, Austria, New Zealand, Ireland, the Netherlands, Switzerland, and Norway, opposed the waiver. Generally, these small countries have little interest in nuclear energy and have strong anti-nuclear policies. They consider the NPT to be the foundation of efforts for nuclear disarmament and to stop nuclear proliferation. These countries wanted tough language to tie strong legally binding nonproliferation conditions with the waiver. Austria, which led the opposition and was the last country to agree to the waiver, has a strong public opinion against nuclear weapons. The Austrian parliament unanimously voted to maintain its antinuclear policies in 1997 (WISE News 1997). The Austrian government found it difficult to support the waiver, with an election on September 28, 2008. Apart from the U.S., Russia, France and Britain urged it to approve the draft. Indian National Security Advisor Narayanan said in an interview that Russia has ${ }^{\circ} \infty$ actually offered to help us with Austria. So they are doing most of the talking ${ }^{\circ} \pm$ (The Hindu 2008). Although Austria approved the draft, it expressed its concerns. Its Foreign Ministry Statement said, "After protracted negotiations, the NSG adopted an exemption for nuclear exports to India...we continue to have concerns on language on testing but we will not block consensus" (CNN-IBN 2008). (Table II)

Although the like-minded states gave priority to their nonproliferation commitment, in the end yielded to the pressure of the big powers. These countries could not tie the nonproliferation conditions with the waiver but expressed their concerns and expectations concerning the waiver in their national statements at the NSG meeting. Now these "like-minded" states are also raising concerns for India's NSG membership (Dahl 2013) but the waiver negotiation shows that major states would again pressurize them not to block the consensus.

$\mathrm{T} 4$ explains the outcome of the deal. At structural level the deal greatly enhanced India's status and the situational logic exhibits both morphostasis, in which India was not given NPT nuclear weapons state status, and morphogenesis, in which India was recognized as a de facto state. (Table III) Norm contestation theory cannot explain why the nonproliferation norm was contested by Russia, France, UK and Italy but remained stable for them and for the United States the norm was flexible enough to carve an Indian exemption by circum- 
venting the rigid nature of the NPT. Morphogenesis theory, on the other hand, by separating the agent, structure and cultural at different time scales have made it possible to uncover the processes that lead to a change or status quo in normative structure. Some agents have powers, capacity and potential to do certain things but not others. These powers come because of a certain position in a structure. Norms are contested and different interpretation lead to variations in their practice but it is the powerful actor that has more leverage to use these norms for its interest and keep these norms flexible. In effect, for weaker actors, norms are more like givens, but for stronger actors, they might be treated as at least potentially variables subject to deliberate adjustment.

\section{CONCLUSION}

The study of norms has made a significant progress in the last two decades. Reflexive understanding of norms highlights the limitation of static understanding of norms and demonstrates that norms are contested throughout their life and therefore, remains in flux. Norms are not only contested, but may create opposition and resistance. Recent scholarship attempts to go beyond the rather static and linear understanding of norms and in this way linear approaches in the "norm life cycle" and the black box of a norm is opened up. However, the study of processes of change in normative structure still faces problems.

Antje Wiener differentiates between behaviorist and reflexive approaches in the study of norms and suggests that scholars working in the conventional constructivism employ a largely behavioral interpretation of international norms where norms are perceived as relatively stable causes for action. She criticized this approach and is in favor of the more reflexive approach to norms where norms are seen as contested and the focus is on the construction of norms in practice as opposed to their influence. The concern with contested meaning is located in practice. Attention is shifted towards social practice to assess the meaning of a norm. This brings up questions concerning the effect of variation in the meanings of norms, as opposed to their direct influence where their meaning is taken as stable even across contexts. This approach, however, does not discuss the question of how far these meanings can be contested.

The concepts of morphogenesis and morphostasis are capable of elaboration and combination in ways that enable us to describe complex norm competition and adaption. Morphogenesis theory demonstrates an intriguing interaction between equilibrating and disequilibrating factors, which suggests that constructivist theory based on the analysis of norm competition and adaptation may be 
able to overcome one of the problems typical to that approach - its focus on stability to the point of denying mechanisms for social change.

India-US nuclear deal demonstrates how material factors dominated the normative concerns and how strategic and economic interests of the United States and other major suppliers changed the nuclear nonproliferation regime without tying India with stronger nonproliferation conditions. States concerned with the nonproliferation were pressurized to yield to the vote for lifting sanctions against India. Morphogenesis theory gives better understanding by taking into account structure, social context, domestic debate and how material factors affect the outcome.

Morphogenesis Theory provides a frame and a terminology to help identify and organize some factors and processes that can help us understand and explain normative contestation and its outcomes - though the results of these processes may be highly contingent rather than easily predictable. Analytical dualism helps to analyze the interrelations between the structure and agency on the one hand and culture and agents on the other hand. Archer emphasizes that the interconnection between culture and agency has been neglected. Interrelated beliefs and ideas have an influence over actors and in order to understand agency it is important to understand the context of these beliefs and ideas and the placement of actors within the social structure and the material resources they can bring to bear on each other. In this way, this theory is a great benefit for research in norms competition and change.

\section{REFERENCES}

Acharya, Amitav. 2004. "How Ideas Spread: Whose Norms Matter? Norm Localization and Institutional Change in Asian Regionalism." International Organization 58(2), 239-275.

Alkopher, Tal Dingott. 2007. "The Role of Rights in the Social Construction of Wars: From the Crusader to Humanitarian Interventions." Millennium: Journal of International Studies 36(1), 1-27.

Agence France Press. 2008. "Japan activist, media denounce Indian nuclear deal." (September 7).

Archer, Margaret. 1995. Realist Social Theory: The Morphogenesis Approach. Cambridge: Cambridge University Press. . 1996. Culture and Agency: The Place of Culture in Social Theory. Cambridge: Cambridge University Press. . 2000. Being Human: The Problem of Agency. Cambridge: Cambridge 
University Press.

Bailey, Jennifer L. 2008. "Arrested Development: The Fight to End Commercial Whaling as a Case of Failed Norm Change." European Journal of International Relations 14(2), 289-318.

Bano, Saira. 2011. The NSG Waiver for India: Implications for the NonProliferation Regime. MSS Dissertation, University of Calgary.

BBC News. 2007. "India and Russia in nuclear deal." (January 25). . 2008a. "India and France in nuclear deal." (September 30). . 2008b. "Britain lifts India nuclear ban." (November 10).

Bell, Coral. 2002-2003. "Normative Shift." The National Interest (Winter).

Bhasker, Roy. 1979. The Possibility of Naturalism: A Philosophical Critique of the Contemporary Human Science. Brighton: Harvester. . 1987. Scientific Realism and Human Emancipation. London: Verso.

Brooks, Stephen G. and William C. Wohlforth. 2005. "Hard Times for Soft Balancing." International Security 30(1), 72-108.

Carlsnaes, Walter. 1992. "The Agency-Structure Problem in Foreign Policy Analysis.” International Studies Quarterly 36(3), 245-270.

Checkel, Jeffery T. 1999. "Norms, Institutions, and National Identity in Contemporary." Europe International Studies Quarterly 43(1), 84-114.

$C N N-I B N, 2008$. "The Big Story: NSG clears nuclear waiver for India." (September 6).

Curry, Bill. 2010. "Canada signs nuclear deal with India." The Globe and Mail (June 28).

Dahl, F. 2013. "Nuclear States Divided on India Joining Export Control Group." Reuters (March 20).

Dessler, David. 1989. "What's at Stake in the Agent-Structure Debate?" International Organization 43(3), 441-473.

Dimitrakopoulos, Dionyssis G. 2008. "Norms, Strategies and Political Change: Explaining the Establishment of the Convention on the Future of Europe." European Journal of International Relations 14(2), 319-341.

Farrell, Theo. 2002. "Constructivist Security Studies: Portrait of a Research Program.” International Studies Review 4(1), 49-72.

Fierke M. Karin. 1996. "Multiple Identities, Interfacing Games: The Social Construction of Western Action in Bosnia." European Journal of International Relations 2(4), 467-498.

. 2003. "Breaking the Silence: Language and Method in International Relations." In F. Debrix ed., Language, Agency and Politics in a Constructed World. Armonk, NY: M. E. Sharpe, 66-86. . 2007. Critical Approaches to International Security. Cambridge: Polity 
Press.

Finnemore, Martha. 1996a. National Interests in International Society. Ithaca: Cornell University Press. . 1996b. "Constructing Norms of Humanitarian Intervention." In Peter J. Katzenstein eds., The Culture of National Security: Norms and Identity in World Politics. NY: Columbia University Press, 153-185.

Finnemore, Martha and Kathryn Sikkink. 1998. "International Norm Dynamics and Political Change." International Organization 52(4), 887-917.

Florini, Ann. 1996. "The Evolution of International Norms." International Studies Quarterly 40(3), 363-389.

Foot, Rosemary and Andrew Walter. 2011. China, the United States, and Global Order. Cambridge: Cambridge University Press.

Giddens, Anthony. 1984. The Constitution of Society. Berkeley: University of California Press.

Gregg, Benjamin. 2003. Coping in Politics With Indeterminate Norms. Albany: SUNY Press.

Haidar, Suhasini. 2014. "India, Australian Seal Civil Nuclear Deal.” The Hindu (September 6).

Hawkins, Darren. 2004. “Explaining Costly International Institutions: Persuasion and Enforceable Human Rights Norms.” International Policy Quarterly 48(4), 779-804.

Hibbs, Mark. 1998. "Russia-India: West May Pressure IMF on Russian reactor Sale." Global Beat Nuclear Watch (June 26).

. 2001. "NSG Objects Again After Russia Says LEU Exports to India Proceeding." Nuclear Fuel (February 5).

Hoffmann, Mathew. 2010. "Norms and Social Constructivism in International Relations.” In Robert A. Denemanee ed., The International Studies Encyclopedia. Oxford: Wiley-Blackwell.

Jacobson, John Kurt. 2003. "Dueling Constructivism: A Post-Morten on the Ideas Debate in Mainstream IR/IPE.” Review of International Studies 29(1), 39-60.

Joshi, Yogesh. 2014. "Despite Modi Visit, Nuclear Impasse Continue to Limit India-Japan Ties.” World Politics Review (September 9).

Kelley, Judith. 2008. "Assessing the Complex Evolution of Norms: The Rise of International Election Monitoring." International Organization 62(2), 221-255.

Kratochwil, Fredrick. 1993. "The Embarrassment of Changes: Neorealism as the Science of Realpolitik without Politics.” Review of International Studies 19(1), 63-80. 
. 2000. "Constructing a New Orthodoxy? Wendt's "Social Theory of International Politics" and the Constructivist Challenge." Millennium: Journal of International Studies 29(1), 73-101.

Kronstadt, Alan K. 2006. "India-U.S. Relations." CRS Issue Brief for Congress (April 6).

Legro, Jeffrey. 1997. "Which Norms Matter? Revisiting the 'Failure' of Internationalism." International Organization 51(1), 31-63.

Mohan, Raja. 2005. "Singh, Bush, press civilian nuclear button." The Indian Express (July 19).

Nevers, Renee De. 2007. "Imposing International Norms: Great Powers and Norm Enforcement." International Studies Review 9(1), 53-80.

Onuf, Nicholas. 1989. World of Our Making: Rules and Rule in Social Theory and International Relations. Columbia: University of South Carolina Press. . 1998. "Constructivism: A User's Manual." In Vendulaka Kubálková, Nicholas Onuf, and Paul Kowert eds., International Relations in a Constructed World. Routledge:M.E. Sharpe, 58-78.

Price, Richard. 2007. The Chemical Weapons Taboo. NY: Cornell University Press. Radyuhin V. 2000. "India, Russia Nuclear Cooperation will Continue." The Hindu (December 17).

Reeker, T. P. 2001. "Russian Shipment of Low Enrichment Fuel to India." US Department of State (February 16).

Reuters. 2010. "U.S., France press for Japan-India nuclear deal.” (June 8).

Rice, Condoleezza. 2000. "Promoting the National Interest." Foreign Affairs (January/February).

Risse-Kappen, Thomas. Ropp, Stephen C, and Kathryn Sikkink. 1999. The Power of Human Rights: International Norms and Domestic Change. Cambridge: Cambridge University Press.

Risse-Kappen, Thomas. 2000. "Let's Argue: Communicative Action in World Politics.” International Organizations 55(1), 1-39.

Sandholtz, Wayne. 2007. Prohibiting Plunder: How Norms Change. NY: Oxford University Press.

Sandholtz, Wayne and Kendall Stiles. 2009. International Norms and Cycles of Change. Oxford: Oxford University Press.

Shannon, Vaughan P. 2000. "Norms Are What States Make of Them: The Political Psychology of Norm Violation.” International Studies Quarterly 40(2), 293-316.

Shannon, Vaughan P. and Keller, Jonathan W. 2007. "Leadership Style and International Norm Violation: The Case of the Iraq War." Foreign Policy Analysis 3(1), 79-104. 
Squassoni, Sharon. 2008. "Looking Back: The 1978 Nuclear Nonproliferation Act." Arms Control Today (December).

Talbott, Strobe. 2004. Engaging India: Diplomacy, Democracy and the Bomb. Delhi/Washington: Viking/Brookings.

Tannanwald, Ninna. 1999. "The Nuclear Taboo: The United States and the Normative Basis of Nuclear Non-Use." International Organization 53(3), 433-468.

The Hindu. 2000. "Legalize India's N-Status, Says Russia." (May 31). . 2008. "Interview of National Security Advisor Narayanan." (August 30).

Thorne E. C. 2001. A Guide to Nuclear Export Controls. Proliferation Data Services.

Varadarajan, S. 2008. "Why China did what it did at NSG." The Hindu (September 7).

Waltz, Kenneth. 1979. Theory of International Politics. Reading, MA: AddisonWesley.

Wendt, Alexander. 1987. "The Agent-Structure Debate Problem in International Relations Theory." International Organization 41(3), 335-370.

White House Press Release. 2005. Joint Statement between George W. Bush and Prime Minister Manmohan Singh. Washington D.C. 8 July. Available at http://georgewbushwhitehouse.archives.gov/news/releases/2005/07/ 20050718-6.html

Wiener, Antje. 2004. "Contested Compliance: Interventions on the Normative Structure of World Politics.” European Journal of International Relations 10(2), 189-234. . 2007. "Contested Meaning of Norms: A Research Framework." Comparative European Politics 5(1), 1-17. . 2008. The Invisible Constitution of Politics: Contested Norms and International Encounters. Cambridge: Cambridge University Press. . 2009. "Enacting Meaning-In-Use: Qualitative Research on Norms and International Relations." Review of International Studies 35(1), 175-193.

Wiener, Antje and Puetter U. 2009. "The Quality of Norms is What Actors Make of It Critical Constructivist Research on Norms." Journal of International Law and International Relations 5(1), 1-16.

WISE News. 1997. "Coalition of Nuclear-Free Countries: Anti-nuclear resolution of the Austrian Parliament.” (September 26). 